\title{
A FRAMEWORK FOR EVALUATING THE PREPONDERANCE-OF-THE-EVIDENCE STANDARD
}

\author{
NeIL OrLOFF $\dagger$ \\ JERY STEDINGER ††
}

After all the evidence at a trial has been presented, a jury is often still in doubt as to the true facts of the case. The law solves this problem in a simple way-through its imposition of the burden of persuasion. This doctrine identifies the party bearing the burden of persuasion for each material issue of fact, and it specifies the degree to which the jury must be convinced by the evidence in order to find in favor of that party. ${ }^{1}$ In most civil cases, the requisite degree of persuasion is "by a preponderance of the evidence." This traditionally requires demonstrating that the existence of the contested fact is more probable than its nonexistence. ${ }^{2}$ In a typical tort case, for example, if the jury views the likelihood of the defendant having negligently injured the plaintiff as two-thirds, then the plaintiff will be awarded damages; if the jury views the likelihood as only one-third, then the plaintiff will be denied recovery.

The all-or-nothing charter of this rule has produced substantial controversy. Critics ask why there should be full recovery when the probability of the events having actually taken place as alleged is just slightly greater than one-half, whereas there is no recovery when the probability is just slightly less than one-half. ${ }^{3}$ The dramatic difference

† Professor of Environmental Law and Policy, Cornell University-College of Engineering. B.S. 1964, Massachusetts Institute of Technology; M.B.A. 1966, Harvard University; J.D. 1969, Columbia University.

\# Assistant Professor of Environmental Engineering, Cornell University-College of Engineering. B.A. 1972, University of California-Berkeley; A.M. 1974, Ph.D. 1977, Harvard University.

The authors wish to thank Kevin Clermont, Ron Ehrenberg, David Kaye, and Faust Rossi for their helpful comments on a draft of this Article.

1 For a general discussion of the doctrine of burden of "proof," see McCormick's HandBoOK OF THE LAw OF Evidence 783-802 (E. Gleary 2d ed. 1972) [hereinafter cited as McCormick]; F. James \& G. Hazard, Givil Procedure 240-53 (2d ed. 1977). There are actually two facets of the burden of proof: the burden of production-i.e. the burden of coming forth with some initial evidence-and the burden of persuasion-i.e. the burden of convincing the jury beyond some stated standard of doubt. This Article is concerned with only the burden of persuasion and will use only that term.

MCCormick, supra note 1, at 794.

See, e.g., Kaye, The Limits of the Preponderance of the Evidence Standard: Justifiably Naked Statistical Evidence and Multiple Causation, 1982 AM. B. Found. 
in outcome, based on only a very small difference in the weight of the evidence, seems unduly harsh. The crudeness of the rule stands in sharp contrast to the law's development of more flexible rules in other situations, such as those involving comparative negligence and contribution among joint tortfeasers, where the law eschews an all-or-nothing approach and apportions the liability for the harm."

A number of scholars have advocated an alternative approach-the expected value rule-to deal with this problem. ${ }^{5}$ Under this rule, the award of damages is calculated by multiplying the probability that the defendant is culpable by the magnitude of the damages. If the plaintiff suffered damages equal to $\$ 100$ and the likelihood that the defendant caused the harm is two-thirds, then the plaintiff would recover $\$ 67$; if the likelihood is one-third, then the plaintiff would recover $\$ 33 .^{\circ}$

In a recent article, Professor Kaye defended the preponderance-ofthe-evidence standard by pointing out that it results, overall, in fewer dollars being erroneously paid. ${ }^{7}$ Using statistical decision theory techniques, he demonstrated that, if the true state of affairs could be ascertained, the average incorrect payment made under the preponderanceof-the-evidence rule would be less than the average incorrect payment made under the expected value rule. ${ }^{8}$

Research J. 487; King, Causation, Valuation, and Chance in Personal Injury Torts Involving Preexisting Conditions and Future Consequences, 90 YALE L.J. 1353 (1981).

4 W. Prosser, Handbook of the Law of Torts $\$ \S 50,67$, at 305-10, 433-39 (4th ed. 1971).

s See, e.g., Kaye, supra note 3; King, supra note 3, at 1384; cf. Rizzo \& Arnold, Causal Apportionment in the Law of Torts: An Economic Theory, 80 Colum. L. REv. 1399 (1980) (advocating apportioning damages among multiple tortfeasers in accordance with a concept of "relative causation"); Robinson, Multiple Causation in Tort Law: Reflections on the DES Cases, 68 VA. L. REv. 713 (1982) (urging that liability be imposed on multiple defendants in proportion to the risks created by each defendant).

C There is precedent for the award of damages against a defendant when the likelihood of his culpability is substantially less than one-half. In Sindell v. Abbott Laboratories, 26 Cal. 3d 588, 607 P.2d 924, 163 Cal. Rptr. 132, cert. denied, 449 U.S. 912 (1980), the California Supreme Court held that if the plaintiff, who allegedly had been injured by the drug diethylstilbestol (DES), could prove her allegations of negligence and damages, she could recover from the companies that had manufactured the drug in proportion to their respective DES sales. The dissent correctly pointed out that "a particular defendant may be held proportionately liable even though mathematically it is much more likely than not that it played no role whatever is causing plaintiffs injuries." Id. at 616, 607 P.2d at 939, 163 Cal. Rptr. at 147 (emphasis in original); see also Kaye, supra note 3 , at 490 .

Kaye, supra note 3, at 496-500.

8 Professor Kaye demonstrated, formally, that the average of the absolute values of the incorrect payments made under the preponderance-of-the-evidence rule would be less than the average of the absolute values of the incorrect payments made under the expected value rule. Id. 
This Article expands that analysis by looking at the number, size, and distribution of errors under the two rules. It examines the general character of the mistakes made under each of the rules. The analysis shows that there are a number of different measures with which to describe these mistakes, and that neither rule is superior under all of the measures. Accordingly, the Article shows that any single index of the errors emerging under a given rule produces a misleading picture of the overall accuracy of that rule.

\section{EXAMPLE}

The following highly simplified example will be used throughout the Article to provide a concrete sense for the more generally developed mathematical results. ${ }^{\circ}$ Hypothesize a chemical factory that employs 400 workers to produce phenoxy acids for herbicides. Assume that 300 of the workers develop stomach cancer and seek compensation from their employer, and that the only issue is whether the injury is work-related. Large-scale epidemiological studies show that the incidence of stomach cancer among individuals similarly exposed to phenoxy acids is consistent around the country and approximately three-fourths. These studies also show, however, that one-fourth of the general population develops stomach cancer as a result of other causes. Finally, assume that every case of employee stomach cancer involves the same damages, which we denote as D.

\section{NUMber of ERrors}

Each of the workers who develops stomach cancer in our example will be able to demonstrate that it is statistically more probable than not that his injury was "caused" by working in the factory. This readily follows from the epidemiological studies linking exposure to phenoxy acids with a high incidence of the disease and demonstrating a much lower incidence of the disease among the general population. The studies predict that 300 of the exposed workers will contract stomach cancer; and, in our example, 300 of the employees actually do contract cancer. On average, 100 of these workers would have developed cancer due to natural causes. The other 200 workers represent the expected number of additional cases of cancer associated with employment in the factory. Accordingly, the probability that any single worker who develops cancer actually contracted the disease as a result of his employment

- This example represents a slight modification of the one used by Professor Kaye, id. at $492-93$. 
is $200 / 300$ or two-thirds. ${ }^{10}$

Under the preponderance-of-the-evidence rule, each of the 300 workers will prevail, because the probability that his injury is workrelated is greater than one-half. ${ }^{11}$ Since approximately two-thirds of the cancers were in fact caused by the chemical factory, two-thirds of these cases will be decided correctly. The remaining one-third of the cases-those in which the cancer was caused by other factors not attributable to the company-will be decided erroneously.

Under the expected value rule, each of the 300 workers will receive damages in the amount of $2 / 3 \mathrm{D}$ (the probability that the cancer was "caused" by exposure in the workplace $(p=2 / 3)$ times the amount of the damages (D)). Accordingly, each of the 300 cases will be decided erroneously. The 200 workers whose damages were actually caused by the factory will receive $1 / 3 \mathrm{D}$ too little, whereas the 100 cases where the damages were not caused by the factory will receive $2 / 3 \mathrm{D}$ too much.

As a general proposition, the number of errors ${ }^{12}$ under the preponderance-of-the-evidence rule is:

No. of Errors $=(1-p) \times$ (No. of Cases)

No. of Errors $=\mathrm{p} \times$ (No. of Cases)

when $\mathrm{p}>1 / 2$

when $\mathrm{p} \leq 1 / 2$

where $p=$ probability that the defendant is culpable under

10 This is correct to a first-order approximation, but it ignores a second-order effect. While some of the 300 workers will have contracted cancer solely from exposure in the workplace and some will have contracted cancer solely from natural causes, some will have contracted cancer from both exposure in the workplace and natural causes. This latter category of cases occurs when nature and the company "each shoot a gun." See generally Summers v. Tice, 33 Cal. $2 d$ 80, 119 P.2d 1 (1948). Who should be viewed as liable in such a situation? See Rizzo \& Arnold, supra note 5, for a discussion of this problem and a proposed methodology for the apportionment of liability in such cases. In most contexts, this second-order effect can be ignored. When the occurrence of each cause is independent of the occurrence of other causes, the frequency with which the two factors act simultaneously is the product of the probabilities associated with each factor. If each probability is small, the product is very small and can be disregarded.

${ }_{11}$ The workers will prevail, provided the court accepts the introduction of "justifiably naked statistical evidence." See Kaye, supra note 3, at 492 n.22. Many courts have not been receptive to purely statistical evidence where no substantial foundation has been laid for the statistical analysis. See, e.g., People v. Collins, 68 Cal. 2d 319, 438 P.2d 33, 66 Cal. Rptr. 497 (1968); State v. Sneed, 76 N.M. 349, 414 P.2d 858 (1966). But see Kaminsky v. Hertz Corp., 94 Mich. App. 356, 288 N.W.2d 426 (1979). Scholars have also expressed reservations at the use of explicitly statistical evidence to aid factfinding. See, e.g., Tribe, Trial by Mathematics: Precision and Ritual in the Legal Process, 84 HaRv. L. REv. 1329 (1971).

${ }_{12}$ Throughout this Article, references to measures such as the number of errors or the overall size of the errors refer to the expected value of the attribute under scrutiny. The equations assume that a large number of cases are subjected to the applicable burden-of-persuasion rule, and calculate the average magnitude of the measure being analyzed. The outcome in a single lawsuit or very small number of lawsuits may differ from this figure. 
the true state of the facts.

In contrast, under the expected value rule:

No. of Errors $=$ No. of Cases

provided $\mathrm{p} \neq 0$ or 1 .

Which rule is superior? In our example, the preponderance-ofthe-evidence rule resulted in 100 errors, and the expected value rule resulted in 300 errors. More generally, since $0<p<1$ in every case, the preponderance-of-the-evidence rule always results in fewer erroneously decided cases. However, this measure tells us nothing about the size of errors and the distribution of the errors among plaintiffs and defendants. ${ }^{13}$ It is to these more illuminating measures that we now turn.

\section{SIZE OF ERRorS}

\section{A. Magnitude of the Mistakes}

The sum of the wrongful payments under the two rules presents another measure of their relative desirability. The smaller the overall size of the wrongful payments under a rule, the more desirable, ceteris paribus, the rule.

A "wrongful payment" can arise in two situations. First, whenever the defendant pays the plaintiff in a lawsuit where, under the true state of the facts, the defendant would have been found innocent, ${ }^{14}$ there is a wrongful payment. Second, whenever the plaintiff fails to recover in a lawsuit where, under the true state of the facts, the plaintiff would be entitled to recovery, ${ }^{15}$ there is a wrongful "payment" - that is, the damage is wrongfully paid for by the plaintiff in-

$1 s$ The number or frequency of errors produced under each of the two decision rules forms, by itself, a very weak basis for selecting a superior rule. But see Ball, The Moment of Truth: Probability Theory and Standards of Proof, 14 VAND. L. REv. 807, 817 (1961) (the proper standard of proof is the one that causes the smallest number of mistakes); Kaye, The Laws of Probability and the Law of the Land, 47 U. CHI. L. REv. 34, 35-36 (1979) (the only question in deciding whether to apply probability theory to legal factfinding is "whether the technique would reduce the number of errors in the factfinding"); $c f$. M. Finkelstein, Quantitative Methods In LAw 59-104 (1978) (one of the goals behind the preponderance-of-the-evidence standard is minimization of the number of erroneously decided cases).

14 This is commonly called a "false positive." A false positive occurs whenever a test announces that the attribute for which the test is designed to check does exist in the particular sample, and, in reality, the attribute is absent. A false positive is a "false alarm."

16 This is commonly called a "false negative." A false negative occurs whenever a test fails to find the attribute for which the test is designed to check-yet, the attribute actually exists in the sampled item. 
stead of the defendant. The sum of these two types of wrongful payments for each rule, over all cases, represents the aggregate errors produced by that rule.

In the hypothetical posited above, the preponderance-of-the-evidence test results in 200 cases decided correctly and 100 cases decided incorrectly. No wrongful payment occurs when a case is decided correctly. In each of the incorrectly decided cases, there is a wrongful payment of $\mathrm{D}$. Accordingly, the magnitude of the wrongful payments under the preponderance-of-the-evidence rule, for all of the cases, is $100 \mathrm{D}$.

The expected value rule results in 300 incorrectly decided cases; however, the size of the wrongful payment is not the same in each of these cases. In 200 of the cases, the chemical company in fact caused the injury and a payment of $1 / 3 \mathrm{D}$ was wrongfully withheld. The total of wrongfully withheld payments equals $67 \mathrm{D}$. In 100 of the cases, the chemical company did not in fact cause the cancer and an excessive payment of $2 / 3 \mathrm{D}$ was wrongfully made. The total wrongful payments for these 100 cases is $67 \mathrm{D}$. The magnitude of the wrongful payments under the expected value rule for all 300 cases is, accordingly, $67 \mathrm{D}+$ $67 \mathrm{D}$, or $134 \mathrm{D}$.

As a general proposition, the sum of the wrongful payments under the preponderance-of-the-evidence rule is:

$$
\begin{aligned}
\text { Wrongful Payments } & =\begin{array}{l}
\text { No. of Wrongly } \\
\text { Decided Cases }
\end{array} \begin{array}{c}
\text { Magnitude of } \\
\text { Wrongful Payment }
\end{array} \\
& =(1-p) \times(\text { No. of Cases) } \times D \\
& =(1-p) D \times \text { (No. of Cases) for } p>1 / 2 .{ }^{16}
\end{aligned}
$$

Under the expected value rule:

$$
\begin{aligned}
& \text { Wrongful Payments }=\begin{array}{l}
\text { No. of Wrongly } \\
\text { Decided Cases }
\end{array} \times \begin{array}{c}
\text { Magnitude of } \\
\text { Wrongful Payment }
\end{array} \\
& =\mathrm{p} \times\left(\begin{array}{c}
\text { No. of } \\
\text { Cases }
\end{array}\right) \times(1-\mathrm{p}) \mathrm{D}+(1-\mathrm{p}) \times\left(\begin{array}{c}
\text { No. of } \\
\text { Cases }
\end{array}\right) \times \mathrm{pD} \\
& =2 \mathrm{p}(1-\mathrm{p}) \mathrm{D} \times \text { (No. of Cases). }
\end{aligned}
$$

16 When $\mathrm{p} \leq 1 / 2$, the magnitude of the wrongful payments is:

$$
\begin{aligned}
\text { Wrongful Payments } & =\begin{array}{l}
\text { No. of Wrongly } \\
\text { Decided Cases }
\end{array} \times \begin{array}{c}
\text { Magnitude of } \\
\text { Wrongful Payment }
\end{array} \\
& =\mathrm{p} \times(\text { No. of Cases }) \times \mathrm{D} \\
& =\mathrm{pD} \times \text { (No. of Cases). }
\end{aligned}
$$


Accordingly, the wrongful payments under the preponderance-of-theevidence rule are always less than the wrongful payments under the expected value rule. This can be seen easily by forming the ratio:

Wrongful Payments

$\frac{\text { Under P-O-T-E Rule }}{\text { Wrongful Payments }}=\frac{(1-\mathrm{p}) \mathrm{D} \times \text { (No. of Cases) }}{2 \mathrm{p}(1-\mathrm{p}) \mathrm{D} \times \text { (No. of Cases) }}$

Under E-V Rule

$$
=\frac{1}{2 \mathrm{p}}<1, \text { whenever } \mathrm{p}>1 / 2 .^{17}
$$

\section{B. Large Mistakes}

A second and quite different way of viewing the size of the errors under the two rules is to focus on large errors. One might wish to employ a rule which minimizes large errors, even though the overall wrongful payments are not necessarily minimized, because of a belief that individuals are much more willing to accept small errors than large ones in a case involving them. A large error is more jolting to a sense of fairness than a small error; it more readily leads to a cry of injustice.

While there is no "natural" index of large errors, statisticians frequently measure the degree of deviation between a series of reported outcomes and their true values by adding together the square of the difference between each outcome and its true value. ${ }^{18}$ This effectively weights each error by the size of the error. The greater the error, the greater the weighting factor, and, accordingly, the greater the measure of large errors.

Under the preponderance-of-the-evidence rule, each of the 100 in-

27 This conclusion holds both when $\mathrm{p}>1 / 2$ and when $\mathrm{p}<1 / 2$. When $\mathrm{p}<1 / 2$ :

$$
\begin{aligned}
& \begin{array}{l}
\text { Wrongful Payments } \\
\text { Under P-O-T-E Rule }
\end{array}=\frac{\mathrm{pD} \times \text { (No. of Cases) }}{2 \mathrm{p}(1-\mathrm{p}) \mathrm{D} \times \text { (No. of Cases) }} \\
& \begin{array}{l}
\text { Wrongful Payments } \\
\text { Under E-V Rule }
\end{array} \\
& =\frac{1}{2(1-\mathrm{p})}<1 \text {, whenever } \mathrm{p}<1 / 2 .
\end{aligned}
$$

The only exception to the general conclusion occurs where $p=1 / 2$. In this case, the sum of the wrongful payments under the two rules is the same. (1979).

18 See, e.g., D.S. Moore, Statistics: Concepts and Controversies 166-70 
correctly decided cases involves a wrongful payment, or error, of D. Thus, the measure of large errors under this rule is $100 \mathrm{D}^{2}$. In contrast, under the expected value rule, the measure of large errors is $200(1 / 3 \mathrm{D})^{2}+100(2 / 3 \mathrm{D})^{2}=67 \mathrm{D}^{2}$.

From the perspective of large errors, then, the relative superiority of the rules turns out to be opposite that which arises by simply looking at the sum of all the errors. When each error is weighted by the size of the error, the sum of all the weighted errors, over any group of cases, is less under the expected value rule than under the preponderance-ofthe-evidence rule. The expected value rule produces, in this sense, fewer large errors than does the preponderance-of-the-evidence rule.

As a general proposition, under the preponderance-of-the-evidence rule:

Measure of
Large Errors

$$
\begin{aligned}
& =(1-p) \times \text { (No. of Cases) } \times D^{2} \quad \text { when } p>1 / 2 \\
& =p \times \text { (No. of Cases) } \times D^{2} \quad \text { when } p \leq 1 / 2
\end{aligned}
$$

Under the expected value rule:

Measure of

Large Errors

$$
\begin{aligned}
= & \text { sum }\left(\begin{array}{c}
\text { Magnitude of the Error } \\
\text { in Each Case }
\end{array}\right)^{2} \\
= & p \times(\text { No. of Cases }) \times((1-p) D)^{2}+ \\
& (1-p) \times(\text { No. of Cases }) \times(p D)^{2} \\
= & p(1-p) \times \text { (No. of Cases) } \times D^{2}
\end{aligned}
$$

It readily follows that the expected value rule produces fewer large errors, under the above definition, than does the preponderance-of-theevidence rule. ${ }^{10}$ This can be seen by forming the ratio: the same.

19 When $p=1$ or 0 , the sum of the squares of the errors under the two rules is 
Measure of Large Errors

$\frac{\text { Under P-O-T-E Rule }}{\text { Measure of Large Errors }}=\frac{(1-\mathrm{p}) \times \text { (No. of Cases) } \times \mathrm{D}^{2}}{\mathrm{p}(1-\mathrm{p}) \times \text { (No. of Cases) } \times D^{2}}$ when $\mathrm{p}>1 / 2$

Under E-V Rule

$$
=\frac{1}{\mathrm{p}} \text { when } \mathrm{p}>1 / 2
$$

Measure of Large Errors

$\frac{\text { Under P-O-T-E Rule }}{\text { Measure of Large Errors }}=\frac{\mathrm{p} \times \text { (No. of Cases) } \times \mathrm{D}^{2}}{\mathrm{p}(1-\mathrm{p}) \times \text { (No. of Cases) } \times \mathrm{D}^{2}}$ when $\mathrm{p} \leq 1 / 2$

Under E-V Rule

$$
=\frac{1}{1-\mathrm{p}} \text { when } \mathrm{p} \leq 1 / 2
$$

Since the probability " $p$ " is always less than 1, each of these fractions will always be greater than 1 . Accordingly, the measure of large errors under the preponderance-of-the-evidence standard will always be greater than the measure of large errors under the expected value standard.

Which criterion is more important: minimizing total errors or minimizing large errors? Each criterion measures the degree of accuracy of the decision rules, but they measure accuracy in different ways.

The theory of utility demonstrates that the impact of a charge imposed upon an individual is not proportional to the size of the charge. ${ }^{20}$ A person may be quite willing to bet $\$ 1.00$ that a quarter, when flipped, will turn up heads, if the reward for heads is $\$ 2.50$, but be unwilling to enter into the same wager when the stakes are $\$ 100,000$ and $\$ 250,000$. Small losses can often be paid "out-of-pocket" or from savings, and impose little hardship. Large losses can force a person to sell his residence, reduce his standard-of-living, or cause bankruptcy, and, accordingly, involve substantial hardship. The degree of hardship actually imposed by a given charge increases geometrically with the size of the charge.

The use of a loss function that treats each "unit of error" equally ignores the disproportionate difference in hardship caused by large errors. By grouping together all errors, it obscures the greater weight that

20 See Kaplan, Decision Theory and the Factfinding Process, 20 Stan. L. REv. 1065, 1069 \& n.4 (1968). See generally R.D. LuCE \& H. RaIfFA, Games AND DeciSIONS 12-38 (1957). 
ordinarily should be given to these errors.

The use of such a linear loss function also obscures the fact that corporations typically have much greater financial resources at their disposal than do individuals. A large firm is unlikely to be hurt by an erroneous payment that would dwarf the lifetime income of a worker. Moreover, large corporations are in a far superior position-both from an informational perspective and a financial reserve perspective-to acquire insurance against potential risks. Thus, the impact of an error also depends heavily on the nature of the party that has to absorb the error.

Overall, the degree of hardship per unit of error depends upon two separate factors: the size of the error and the character of the party on whom the error falls. Accordingly, in designing a system that minimizes losses, one should ordinarily employ a nonlinear function that gives greater weight to large errors. ${ }^{21}$ This more closely approximates the actual disutility associated with such errors. Treating all units of error equally assumes a factual situation that frequently does not accord with reality.

\section{Distribution OF ERRORS}

The distribution of the errors under each rule reflects the degree of bias produced by the rule. ${ }^{22}$ When the payments wrongfully made by defendants equal the payments wrongfully withheld from plaintiffs, there is no bias in the decision rule. In contrast, when the errors systematically fall more heavily on one side or the other, there is bias. The inquiry here is into the degree to which the errors under each of the rules fall unevenly among plaintiffs and defendants. ${ }^{23}$

Under the preponderance-of-the-evidence rule, each of the one hundred incorrectly decided cases results in an erroneous payment by the chemical company of damages equal to $D$. None of the wrongful

21 The loss function, ideally, should take into account the actual disutility associated with each size of error for each party. Thus, it should reflect the fact that what appears as a large error to an individual would often be construed as a relatively minor matter to a major corporation. However, the administrative costs for developing each party's utility curve, in every lawsuit, are likely to be prohibitively high.

32 A decision rule is unbiased if it does not systematically overstate or understate the true value of the variable being measured. See generally D.S. MoorE, supra note 18 , at $106-10$.

${ }^{23}$ A goal of equalizing errors among plaintiffs and defendants reflects a notion of "blindfolded" justice. It reflects the view that false positives and false negatives deserve equal weight. There are, of course, several exceptional areas where this does not represent society's values. In the field of criminal law, for example, society accepts that many individuals who in fact are guilty will be found innocent in order to ensure that innocent people are much less likely to be found guilty. 
payments fall on plaintiffs, because no plaintiff who should have been compensated, under the true state of the facts, is denied recovery.

The situation would be reversed, of course, if in our example the probability of the company's culpability was less than one-half. Then, because none of the workers would recover from the company, all of the wrongful payments (the uncompensated damages borne by the employees whose cancer was, in fact, caused by exposure in the workplace) would fall on the plaintiffs. When $\mathrm{p} \leq 1 / 2$, none of the wrongful payments fall on the company.

Under the expected value rule, the wrongful payments are much more evenly distributed. The 200 plaintiffs who should have recovered $\mathrm{D}$ but were only awarded $2 / 3 \mathrm{D}$ are collectively undercompensated by 66 D. The 100 plaintiffs who should have received nothing but were awarded $2 / 3 \mathrm{D}$ are collectively overcompensated by $66 \mathrm{D}$. As a group, then, the plaintiffs receive neither more nor less than they should receive under the true state of the facts; similarly, the defendant pays exactly the amount for which he is liable under the true state of the facts.

More generally, under the preponderance-of-the-evidence rule, the distribution of the errors is always lopsided. When the probability of the defendant's liability is less than or equal to one-half, all the errors fall on the plaintiffs. When the probability of defendant's liability is greater than one-half, all the errors fall on the defendant. ${ }^{24}$

Under the expected value rule, the decision is wrong in each individual case; but, the collective errors that fall on the plaintiffs cancel each other out, and the collective errors that fall on the defendant cancel each other out. While some plaintiffs are under-compensated and others are over-compensated, they receive, as a group, exactly the amount to which they are entitled. Similarly, the defendant pays, overall, exactly the amount that it owes under the true state of the facts. Its instances of over-compensation also are offset by its instances of undercompensation. Under the expected value rule, then, the burden of wrongful payments that falls on each group as a whole is not only

24 Because of the bias inherent in the preponderance-of-the-evidence rule, particularly when a single defendant faces lawsuits by many plaintiffs and the probability of liability is the same in each case, Professor Kaye has argued that in such circumstances the expected value rule is preferable. Kaye, supra note 3 , at 502 . In all other circumstances, Professor Kaye argues the preponderance-of-the-evidence rule is superior. The problem with this framework is that the call to switch decision rules in a specific case emerges only as a result of factors wholly outside the particular case at bar. It depends on the existence of other lawsuits involving the same defendant and the same set of facts. It seems awkward, if not unworkable, to radically change the decision rule in a specific lawsuit depending upon what other plaintiffs may do in other lawsuits. 
equal, but also turns out to be nonexistent.

The unbiased character of the expected value rule occurs regardless of the probability of the defendant's culpability. Unlike the situation under the preponderance-of-the-evidence rule, the pattern of the distribution of errors between the plaintiffs and the defendant is not affected by the weight of the evidence.

What happens, though, when one aggregates all lawsuits involving exposure of workers to asbestos, or all lawsuits involving exposure to Agent Orange, or all lawsuits involving traffic accidents-or all civil litigation? Are the results different when one aggregates a large number of lawsuits involving different probabilities rather than, as in our example, a large number of lawsuits involving the same probability? Would the preponderance-of-the-evidence standard then result in an unbiased distribution of errors? ${ }^{25}$

Under one unlikely factual situation, it would. If, for any group of lawsuits, the average of the probabilities associated with the lawsuits happened to equal the proportion of the lawsuits whose probability was greater than one-half, then the preponderance-of-the-evidence rule would be unbiased when applied to that group. In other words, if one found that the average of all the p's in the group exactly equalled the percentage of the p's that were greater than one-half, then the erroneous payments that would fall on the defendants would balance the erroneous payments that would fall on the plaintiffs. ${ }^{26}$

${ }^{25}$ See Kaye, supra note 3, at 503 ("On balance, [the preponderance-of-the-evidence standard produces] no systematic unfairness . . . despite the apparent 'bias' for fixed values of [p]." Based on this conclusion, Professor Kaye argues for the general use of the preponderance-of-the-evidence rule.).

${ }^{28}$ If there are $n$ cases in a group of lawsuits, with an average probability of $\bar{p}$ of defendants having caused the injuries, then the expected value rule would require the defendants to pay total damages of $n \overline{p D}$. Since the expected value rule has been shown to be unbiased, $n \bar{p} D$ represents the amount that the defendants must pay under the preponderance-of-the-evidence rule for it also to be unbiased.

Assume that, among the $n$ cases in the group, $m$ have probabilities greater than $1 / 2$. Then, under the preponderance-of-the-evidence rule, the total payments by the defendants will be $\mathrm{mD}$. Accordingly, the preponderance-of-the-evidence rule will be unbiased only if $\mathrm{n} \overline{\mathrm{p}} \mathrm{D}=\mathrm{mD}$ or, equivalently, $\overline{\mathrm{p}}=\mathrm{m} / \mathrm{n}$. The preponderance-of-the-evidence rule will be unbiased only if the average probability of all the lawsuits in the group equals the frequency with which the p's exceed $1 / 2$.

Note that this derivation continues the assumption we first made-that the damages " $D$ " are the same for each plaintiff. When this assumption is relaxed, the general conclusion does not change; but, the analysis becomes more complex. See infra text accompanying note 29 .

An example may help to illuminate the analysis. Assume that there are four lawsuits in a group with probabilities of $1 / 8,1 / 4,3 / 8$, and $3 / 4$, and that all of the lawsuits involve the same damages " $D$." The average of the probabilities is .38 . The proportion of the probabilities with $p>1 / 2$ is .25 .

For this particular group, the preponderance-of-the-evidence standard will be bi- 
While there are no empirical statistics with which to estimate the distribution of probabilities for different categories of lawsuits, it appears that this hypothesized factual situation is not realistic. Lawsuits are usually not brought where the likelihood of prevailing is very low. This is especially so with personal injury litigation where suits typically are brought under a contingent fee arrangement. This produces a strong incentive among plaintiffs' attorneys to weed out those cases where the probability of success is low. ${ }^{27}$

Accordingly, most classes of lawsuits probably include a higher proportion of cases where the chance of recovery is greater than onehalf. In these situations, the preponderance-of-the-evidence rule will be biased in favor of plaintiffs.

The situation is somewhat more complex when one aggregates all lawsuits that might be brought rather than all lawsuits that are actually brought. When the set of cases to be analyzed is expanded to include all plaintiffs who are injured, whether or not they bring a lawsuit, then the normal filtering out of cases with a low probability of success no longer occurs. Would the preponderance-of-the-evidence standard then result in an unbiased distribution of errors?

The answer, again, seems to be "no." There are, perhaps, millions of probabilities associated with this larger set of cases. Some of the potential lawsuits would have very small probabilities; others would have probabilities approaching one; many would fall between these two poles. Yet, it would be extraordinary if the average of all these probabilities equalled or even came close to the proportion having a probability greater than one-half. ${ }^{28}$ Moreover, when one relaxes the assumption that each of the potential lawsuits involves the same damages and moves to the more realistic situation where the lawsuits involve different damages, then it would be just a "fluke" if the necessary distribution of probabilities occurred for the preponderance-of-the-evidence rule to be unbiased. ${ }^{29}$

ased in favor of the defendants. This readily follows from tracing through the payments that will be made. Only one lawsuit will result in the defendants' paying damages (the case where $p=3 / 4$ ). Thus, the total damages paid will be $D$. However, the total damages that should be paid by the defendants in order for the erroneous payments made by the defendants to balance the payments wrongfully withheld from the plaintiffs is $1 / 8 D+1 / 4 D+3 / 8 D+3 / 4 D=1.5 D$ or $150 \%$ of the damages that are required by the preponderance-of-the-evidence standard.

${ }_{27}$ See generally Galanter, Why the "Haves" Come Out Ahead: Speculations on the Limits of Legal Change, 9 LAW AND Soc'Y REv. 95 (1974) (plaintiff's attorneys in personal injury cases generally have a one-time relationship with the client and thus have no client-oriented incentives beyond the outcome of the immediate litigation).

${ }^{28}$ See supra note 26 for a concrete example showing how these two characteristics of a "typical" probability distribution are unlikely to equal each other.

${ }^{20}$ Let the damages associated with lawsuit $\mathrm{k}$ be $\mathrm{D}_{\mathrm{k}}$ and the probability that the 


\section{CONCLUSION}

The above analysis shows the critical importance of the criteria used to select the "best" decision rule. This problem exists even when there is a single objective: reducing errors in factfinding. If the goal is to minimize the number of erroneously decided cases or the sum of the wrongful payments that are made, the preponderance-of-the-evidence rule emerges as the superior choice. However, if the goal is to minimize making large errors or to avoid bias in the distribution of the errors among plaintiffs and defendants, the expected value rule emerges as the superior choice. Neither of the two rules is preferable under all of the tests. $^{30}$

On what basis should one select the criteria to be used to determine the best decision rule? This Article has proceeded on the assumption that the best burden-of-persuasion rule is the one that, in some general sense, results in the fewest errors. A burden-of-persuasion rule, however, is much more than a procedural device for resolving uncertainty at the conclusion of a trial. Professor Robinson has pointed out

defendant in the lawsuit is culpable be $\mathrm{p}_{\mathrm{k}}$. Then, the appropriate total payment by all defendants for a decision rule to be unbiased is:

$$
\sum_{k=1}^{n} p_{k} D_{k} \quad \text { where } n=\text { number of potential lawsuits in the group. }
$$

Let $I_{k}=1$ if $p_{k}>1 / 2$ and $I_{k}=0$ if $p_{k} \leq 1 / 2$. Then the total payment that will be made under the preponderance-of-the-evidence rule is:

$$
\sum_{k=1}^{n} I_{k} D_{k}
$$

The preponderance-of-the-evidence rule will be unbiased only if:

$$
\sum_{k=1}^{n} p_{k} D_{k}=\sum_{k=1}^{n} I_{k} D_{k}
$$

30 This Article has conceptualized the problem as a search for the "true" cause of the harm. Note, though, that one might impose liability not in terms of causation but rather in terms of the imposition of risk. See Robinson, supra note 5 ( in multiple causation cases, liability should be imposed in proportion to the risks created by each defendant); see also Sindell v. Abbott Laboratories, 26 Cal. 3d 588, 607 P.2d 924, 163 Cal. Rptr. 132 (apportioning liability among producers of drug based on market share), cert. denied, 449 U.S. 912 (1980).

This alternative conceptualization of the problem readily leads to selection of the expected value rule over the preponderance-of-the-evidence rule for determining the amount of damages properly due from each defendant. The "factory" and "nature" are viewed as the sources of the risk, and liability is imposed in proportion to the magnitude of the risk created by each "defendant." The company would have to pay for damages in proportion to the risk created by it, and the plaintiff would have to bear the costs associated with the risk created by nature. 
that in some types of situations, it may fully determine liability. ${ }^{31}$ For example, in the context of the DES cases (a series of lawsuits against manufacturers of the drug diethylstilbestrol (DES) alleging that the drug caused cancer in the female offspring of women who took the drug), ${ }^{32}$ "a defendant is no better able to disprove causal responsibility than the plaintiff is to prove it. The placement of the burden, as a practical matter, is dispositive."3s Accordingly, the selection of the burden-of-persuasion rule may substantially affect which segment of society shoulders unavoidable losses.

The most appropriate burden-of-persuasion rule, then, may vary from one type of lawsuit to another. ${ }^{34}$ In every case, the law seeks to minimize errors. But, since the effects of the rule will extend deeply into other policy domains as well, criteria other than error minimization must also be used. ${ }^{35}$ The selection of a burden of persuasion rule may influence, for example, the degree to which pharmaceutical companies are willing to develop and market new drugs. It may affect innovation in the chemical pesticides industry. It may influence the extent to which individuals and companies alike take out insurance, and, accordingly, the extent to which the cost of injuries is spread over broad segments of society. ${ }^{38}$

Studies of jury deliberations suggest that jurors readily appreciate the need to apply different burden of persuasion rules to different situations. ${ }^{37}$ Although jurors are usually instructed in civil cases to apply the preponderance-of-the-evidence rule, they frequently apply the expected value rule. Where there is uncertainty over the plaintiff's right to re-

31 Robinson, supra note 5 , at 729 .

32 E.g., Sindell v. Abbott Laboratories, 26 Cal. 3d 588, 607 P.2d 924, 163 Cal. Rptr. 132, cert. denied, 449 U.S. 912 (1980).

ss Robinson, supra note 5 , at 729 .

34 Indeed, the most appropriate burden-of-persuasion rule may vary among the different issues in a single lawsuit. For example, one might impose a higher burden-ofpersuasion requirement in connection with the determination of liability than in connection with the determination of the amount of damages.

ss See, e.g., G. Calabresi, The Cost of Accidents (1970); Coase, The Problem of Social Cost, in Economics of THE ENvironment 156-66 (R. Dorfman \& N. Dorfman $2 \mathrm{~d}$ ed. 1977) (liability in tort should not be imposed on the party causing the damage, but on the party who can prevent the damage at the smallest cost).

${ }^{36}$ Reflecting the variety of policies effectuated by the burden-of-proof rule, the law currently applies different burdens of persuasion to different situations. In criminal cases, the burden of persuasion is "beyond a reasonable doubt." In a few exceptional civil cases, a higher standard is imposed than a preponderance-of-the-evidence-a requirement of "clear and convincing evidence." This higher standard applies to: (1) charges of fraud, (2) suits to establish the terms of a lost will, and (3) suits for the specific performance of an oral contract. See MCCoRMICK, supra note 1, at 793-98.

s7 See generally H. Kalven \& H. Zeisel, The AMerican Jury 163-67 (1966) (judges and jurors sometimes interpret burden-of-proof rules differently in close cases). 
cover, a jury may reduce the amount of the award, for example from $\$ 150,000$ to $\$ 100,000$, to reflect this uncertainty. Similarly, a jury will on occasion modify its proposed award as a result of its views on the impact of the proposed judgment on the specific parties to the litigation.

This lessens the force, as a practical matter, for abandoning the preponderance-of-the-evidence standard, even in those situations where it appears least appropriate. When jurors sense the need to apply a different burden of persuasion requirement, they often do so. ${ }^{\mathbf{3 8}}$ Of course, this does not obviate the need to carefully construct standards applicable to each category of lawsuits. It shows, though, that the existing legal system has more flexibility than appears from simply looking at the instructions given to juries. ${ }^{39}$

Overall, then, this Article demonstrates that designing the best burden of persuasion rule is more complex than has been suggested..$^{40}$ Even when the objective is to minimize errors, the analysis shows that no single, general answer to the question is possible.

s8 Id. at 166 .

${ }^{39}$ See Kalven, The Dignity of the Civil Jury, 50 VA. L. REv. 1055, 1071 (1964) ("Reform of private law is notoriously hard to effectuate, and in the long interim there is room for the jury's touch. Further, there is not inconsiderable evidence that jury resistance to a rule is often a catalyst of change.").

In the federal district courts, approximately $70 \%$ of all cases are decided by a judge without a jury. 1980 Proc. OF Jud. Conf. OF THE U.S. 404 (table C-7). This lessens the degree to which jury resistance to a rule may be relied upon to produce change.

10 Note, also, that the two rules impose substantially different administrative costs on society. The preponderance-of-the-evidence rule filters out cases where, even though the damages are high, the likelihood of prevailing is low. Many of these cases would be brought under the expected value rule because plaintiffs would be virtually assured of some recovery to pay for the ligitation.

Moreover, for every lawsuit that goes to trial, the expected value rule injects an additional issue into the litigation. On top of all the issues otherwise present in the case, the parties also have to litigate the magnitude of the probability " $p$ " that the defendant caused the damage. Thus, in terms both of the number of lawsuits and the number of issues in each lawsuit, the preponderance-of-the-evidence rule is an "efficient" way to resolve uncertainty in factfinding compared to the expected value rule. 